https://helda.helsinki.fi

\title{
Maternal drug or alcohol abuse is associated with decreased head size frommid-pregnancy to childhood
}

\section{Lehikoinen, Anni}

2016-07

Lehikoinen , A , Orden , M-R , Heinonen , S T \& Voutilainen, R 2016 , ' Maternal drug or alcohol abuse is associated with decreased head size frommid-pregnancy to childhood ', Acta Paediatrica , vol. 105 , no. 7 , pp. 817-822 . https://doi.org/10.1111/apa.13416

http://hdl.handle.net/10138/164841

https://doi.org/10.1111/apa.13416

publishedVersion

Downloaded from Helda, University of Helsinki institutional repository.

This is an electronic reprint of the original article.

This reprint may differ from the original in pagination and typographic detail.

Please cite the original version. 


\section{Maternal drug or alcohol abuse is associated with decreased head size from mid-pregnancy to childhood}

Anni Lehikoinen (anni.lehikoinen@kuh.fi) ${ }^{1}$, Maija-Riitta Ordén², Seppo Heinonen²,3, Raimo Voutilainen ${ }^{1}$

1.Department of Pediatrics, University of Eastern Finland and Kuopio University Hospital, Kuopio, Finland

2.Department of Obstetrics and Gynecology, Kuopio University Hospital, Kuopio, Finland

3.Department of Obstetrics and Gynecology, Helsinki University Hospital and University of Helsinki, Helsinki, Finland

\section{Keywords}

Foetal alcohol spectrum disorders, Griffiths Mental Developmental Scales, Head circumference, Threedimensional imaging, Ultrasound

\section{Correspondence}

Anni Lehikoinen, MD, Department of Pediatrics, Kuopio University Hospital, PO Box 100, Fl-70029 Kuopio, Finland.

Tel: +35817173311

Fax: +35817172410

Email: anni.lehikoinen@kuh.fi

Received

23 December 2015; revised 29 January 2016; accepted 31 March 2016.

DOI:10.1111/apa.13416

\begin{abstract}
Aim: Maternal alcohol abuse is poorly recognised and causes developmental problems. This study explored the foetal central nervous systems (CNS), head circumference and psychomotor development of children exposed to drugs or alcohol during pregnancy up to 2.5 years of age.
\end{abstract}

Methods: We recruited 23 pregnant women referred to Kuopio University Hospital, Finland, by their family doctor because of drug or alcohol abuse, and 22 control mothers. Foetal CNS parameters were measured by three-dimensional ultrasonography at the mean gestational age of 20 weeks and the Griffiths Mental Developmental Scales (GMDS), and anthropometric measurements were carried out at the mean ages of one and 2.5 years. Results: The exposed foetuses had decreased biparietal and occipito-frontal distances and head circumferences, but unchanged cerebellar volume at 20 weeks, and decreased head circumferences and length and height at birth, one and 2.5 years of age. They scored lower than the controls on the GMDS general quotient and the hearing, language and locomotor subscales at 2.5 years of age.

Conclusion: Maternal alcohol or drug exposure was associated with decreased head size from mid-pregnancy to childhood and reduced development at 2.5 years. Foetal head circumference at mid-pregnancy was a useful indicator of substance abuse affecting the CNS.

\section{INTRODUCTION}

Previous studies have shown that only a minority of pregnant women who abuse alcohol, drugs and medication are recognised by healthcare providers and receive the help they need $(1,2)$. The prevalence of alcohol and drug consumption during pregnancy has also been shown to vary in different countries (3).

Foetal alcohol spectrum disorders (FASD) is the umbrella term for all foetal alcohol effects (4). The children at the severe end of this spectrum - the complete phenotype - have been defined as having foetal alcohol syndrome (FAS). FASD also includes partial foetal alcohol syndrome, alcohol-related birth defects and alcohol-related neurodevelopmental disorder. FAS is the leading identifiable, nonhereditary cause of mental retardation in the Western world (5). Although a diagnosis of FAS can be made on the basis of physical features, most of the children exposed

\footnotetext{
Abbreviations

CNS, Central nervous system; FAS, Foetal alcohol syndrome; FASD, Foetal alcohol spectrum disorders; GMDS, Griffiths Mental Developmental Scales.
}

prenatally to alcohol do not show these physical markers (6).

True to form, the morphological effects of alcohol on the foetal central nervous system (CNS) vary from undetectable changes to difficult malformations. The morphological changes detected in children and adults after alcohol exposure during foetal life include microcephaly and cortical atrophy, cerebellar hypoplasia and dysmorphism of the corpus callosum, together with other mid-line structural abnormalities $(7,8)$. Furthermore, prenatal smoking exposure has been reported to be associated with a smaller

\section{Key notes}

- This study explored the foetal central nervous system (CNS), head circumference and psychomotor development of children exposed to drugs or alcohol during pregnancy up to 2.5 years of age.

- Maternal alcohol or drug exposure was associated with decreased head size from mid-pregnancy to childhood and reduced development at 2.5 years.

- Foetal head circumference at mid-pregnancy was a useful indicator of substance abuse affecting CNS. 
frontal lobe and reduced cerebellar volumes in preterm infants (9). Only a few researchers have used foetal ultrasonography in studies of alcohol or drug-exposed foetuses. Kfir et al. (10) demonstrated shorter cavalcalvarial and fronto-thalamic distances during the second trimester and shorter fronto-thalamic and biparietal distances during the third trimester in alcohol-exposed foetuses compared to nonexposed controls. Handmaker et al. (11) demonstrated a smaller transcerebellar diameter and a lower head-to-abdominal circumference ratio in alcoholexposed foetuses at the mean gestational age of 27.3 weeks (range 18.0-41.7 weeks). Wass et al. (12) suggested a connection between the reduction in the foetal frontal brain size and alcohol exposure during pregnancy. In that study, the ultrasonographical examination time varied from 12 to 42 weeks of gestation. Exposure to illegal drugs has also been associated with physical birth defects and increased risk of regulatory and neuropsychological difficulties $(13,14)$.

Three-dimensional (3D) ultrasonography was introduced at the beginning of 1990s, and it has opened up a new way to measure organ volumes quite accurately (15). However, the potential of 3D ultrasonography to detect harmful consequences of alcohol abuse in CNS is unclear. At the same time, early identification of at-risk pregnancies is a strong protective factor for reducing harm from foetal alcohol exposure.

Prenatal alcohol exposure leads to a wide range of problems, and we lack reliable tools to detect early alcohol effects. Our aims were to investigate whether previously reported CNS changes associated with prenatal alcohol exposure were already visible at mid-pregnancy and to evaluate head size, length and height and psychomotor development of exposed children up to the age of 2.5 years.

\section{PATIENTS AND METHODS}

The ultrasound measurements were performed as a part of a longitudinal prospective study conducted in 2005-2008 in the maternity clinic at Kuopio University Hospital, Finland, and the primary healthcare centre in the city of Kuopio. The study protocol was approved by the Research Ethics
Committee of Kuopio University Hospital. All study participants provided informed, written consent.

\section{Patients}

Subjects were recruited from patients at the maternity clinic at Kuopio University Hospital (Table 1). The 23 pregnant women followed up in the maternity clinic had been referred to the clinic by their general practitioners due to concerns about alcohol or drug abuse. The Alcohol Use Disorder Identification Test (AUDIT) (16) was used to identify women with harmful patterns of alcohol consumption. The inclusion criteria were total AUDIT scores of eight or more, alcohol use during the ongoing pregnancy or any drug abuse before or during the pregnancy. The 22 control subjects were recruited from two maternity clinics of the Kuopio city primary healthcare centre. The inclusion criteria for the controls were non-smoking, healthy, an AUDIT score of less than eight before the pregnancy and no alcohol consumption during the ongoing pregnancy. All participants were Finnish Caucasians.

\section{Ultrasound measurements}

3D ultrasound images of the intracranial contents were obtained using a GE Voluson 730 Expert with a 4.08.5-MHz RAB4-8L abdominal probe (General Electric Healthcare, London, UK) as part of a structural ultrasound examination at the gestational age of $18+3$ to $21+6$ weeks. The scans were performed by an experienced fetal medicine specialist (M-RO). All 3D volumes were saved with 4D View software version 6.2 (General Electric Healthcare) for offline examination. At least two volumes were collected for each evaluation from the axial 2D view at the transventricular level. The 3D volumes presenting clearer outlines of the cerebellum were selected for cerebellar calculations. Virtual organ computer-aided analysis was used to measure the total cerebellar volume. The saved ultrasonographical data were analysed by two authors of this study (M-RO and AL).

To achieve a consistent orientation, the following adjustments were performed. In the coronal view, both hemispheres were set symmetrically across the perpendicular line. In the sagittal view, the cerebellum and the nasal bone were set at approximately the same horizontal line. In the

Table 1 Characteristics of the alcohol abusing and control mothers and their pregnancies

\begin{tabular}{|c|c|c|c|c|c|}
\hline & \multicolumn{2}{|c|}{ Abusers $n=23$} & \multicolumn{2}{|c|}{ Controls $\mathrm{n}=22$} & \multirow[b]{2}{*}{$\mathrm{p}$} \\
\hline & Mean & SD & Mean & SD & \\
\hline Number of previous pregnancies & 1.3 & 0.58 & 1.3 & 0.79 & 0.867 \\
\hline Number of previous abortions & 0.7 & 1.15 & 0.3 & 0.60 & 0.315 \\
\hline BMI before pregnancy $\left(\mathrm{kg} / \mathrm{m}^{2}\right)$ & 22.9 & 2.17 & 22.8 & 4.54 & 0.575 \\
\hline Duration of gestation at the time of ultrasound (weeks) & 19.5 & 0.63 & 20.3 & 0.89 & $0.04 *$ \\
\hline Age at delivery (years) & 25.0 & 5.02 & 29.7 & 3.09 & $<0.01 *$ \\
\hline Duration of pregnancy at birth (weeks) & 39.4 & 1.57 & 39.1 & 1.49 & 0.761 \\
\hline
\end{tabular}

Mann-Whitney test was used to test differences between the groups.

* Statistically significant difference, $\mathrm{p}<0.05$. 
transversal view, the hemispheres were set symmetrically across the axis going along the falx cerebri. The correct sagittal position was secured from the transversal view, where the thalamus and cavum septi pellucidi were seen in the same section. This section was also the level for the measurements of the biparietal and occipito-frontal distances and the head circumference.

After the orientation correction, the transversal section at the level of mid-cerebellum was selected for the cerebellar volume and width measurements. After obtaining the ideal plane, the cerebellum was outlined for its external surface manually with the rotation angle of six degrees. By the end of the rotational process, the programme calculated the volume automatically and provided the reconstructed 3D image of the organ.

The maximal length of corpus callosum was obtained after the described orientation from the sagittal view, with the slice thickness set at $0.5 \mathrm{~mm}$, and the volume contrast imaging switched on to optimise the visualisation.

\section{Follow-up of the children}

Midwives and registered nurses assessed the growth measures at birth. The children's psychomotor development was assessed using the Griffiths Mental Developmental Scales (GMDS) 1996 Revision (17) at the age of one year and the GMDS-Extended Revised (18) at the age of 2.5 years. GMDS yields a general quotient of overall development. Standardised developmental subquotients were also created. The developmental domains that were tested were locomotor (gross motor), personalsocial (self-care and social interaction), hearing and language, eye-hand coordination (fine motor) and performance (cognition, symbolic play and puzzles) at the age of one year. Depending on the child's skills, practical reasoning was also tested at the average age of 2.5 years (18). Growth measurements were performed at the mean ages of one and 2.5 years by one of the authors (AL). Sex- and age-specific standard deviation (SD) scores for length and height, birthweight and head circumference were calculated according to the Finnish growth reference $(19,20)$. In addition, weight-for-length and height were determined at the mean ages of one and 2.5 years (19).

\section{Data management and statistics}

Data management and the statistical analyses were performed using SPSS 19 and 21 (SPSS Inc, Chicago, Illinois, USA). For all analyses, a p value of less than 0.05 was considered significant. To test differences between the study groups, univariate analysis by ANOVA was used for the ultrasonographical CNS parameters and the Mann-Whitney test for the GMDS and demographic parameters. The chi-squared test was used for dichotomous variables. The one-sample Wilcoxon signed rank test was used to assess the difference of the exposed children's head circumference, length and height (SD score) and weight (SD score at birth, weight-for-length and height percentage at the mean ages of one and 2.5 years) from the respective median values
(SD score 0, 100\% for weight-for-length and height) of the Finnish growth reference $(19,20)$.

\section{RESULTS}

\section{Foetal ultrasound measurements}

Only 11 subjects and 21 controls agreed to participate in the ultrasonography analyses at mid-pregnancy. Confirmed alcohol exposure was found in 64\% and drug exposure in $82 \%$ of the subjects during the on-going pregnancy. The low quality of the ultrasonography images caused the exclusion of one subject and one control. Dichorionic twins were found in one subject. The head circumferences and the biparietal and occipito-frontal distances of the foetuses were significantly smaller in the exposed women than in the controls, when adjusted for gestational age and maternal smoking status. No significant difference in the corpus callosum or cerebellar measures was detected (Table 2).

\section{Follow-up evaluation}

The demographics of the mothers are given in Table 1 . We carried out a follow-up evaluation of the children's growth characteristics and psychomotor development. At birth, the head circumference, length and weight were significantly smaller in the exposed children than the controls and the Finnish growth reference. At the mean ages of one and 2.5 years, head circumference and length and height remained smaller, but weight-for-length and height did not differ from the national reference. The head circumference to length-height ratio did not differ between the study groups at any age (Table 3).

The GMDS scores did not differ significantly between the exposed and controls at the mean age of one year. Although

\begin{tabular}{|c|c|c|c|c|c|}
\hline \multirow[b]{2}{*}{ Parameter } & \multicolumn{2}{|c|}{$\begin{array}{l}\text { Exposed } \\
\text { foetuses } \\
(n=11)\end{array}$} & \multicolumn{2}{|c|}{$\begin{array}{l}\text { Controls } \\
(n=20)\end{array}$} & \multirow[b]{2}{*}{$\mathrm{p}$} \\
\hline & Mean & SD & Mean & SD & \\
\hline Biparietal distance $(\mathrm{cm})$ & 4.37 & 0.43 & 4.67 & 0.32 & $0.03 *$ \\
\hline Occipito-frontal distance $(\mathrm{cm})$ & 6.04 & 0.40 & 6.37 & 0.39 & 0.049* \\
\hline Fronto-thalamic distance $(\mathrm{cm})$ & 3.08 & 0.34 & 3.40 & 0.27 & 0.62 \\
\hline Caval-calvarial distance $(\mathrm{cm})$ & 2.07 & 0.29 & 2.19 & 0.31 & 0.50 \\
\hline Head circumference $(\mathrm{cm})$ & 16.83 & 1.12 & 17.93 & 1.05 & $0.04^{*}$ \\
\hline Head area $\left(\mathrm{cm}^{2}\right)$ & 22.24 & 2.88 & 25.35 & 3.13 & 0.10 \\
\hline Corpus callosum length $(\mathrm{cm})$ & 2.68 & 0.44 & 2.72 & 0.57 & 0.71 \\
\hline Corpus callosum height $(\mathrm{cm})$ & 1.10 & 0.12 & 1.25 & 0.19 & 0.75 \\
\hline Cerebellar volume $\left(\mathrm{cm}^{3}\right)$ & 0.84 & 0.17 & 1.08 & 0.28 & 0.56 \\
\hline Cerebellar width $(\mathrm{cm})$ & 1.79 & 0.13 & 1.88 & 0.15 & 0.81 \\
\hline Vermis width $(\mathrm{cm})$ & 0.67 & 0.10 & 0.72 & 0.10 & 0.98 \\
\hline Vermis height $(\mathrm{cm})$ & 1.10 & 0.12 & 1.25 & 0.19 & 0.44 \\
\hline Vermis depth $(\mathrm{cm})$ & 0.90 & 0.13 & 0.96 & 0.25 & 0.62 \\
\hline
\end{tabular}

Univariate analysis by ANOVA was used to test differences between the groups. p Values are adjusted for gestational age (GA) and smoking. *Statistically significant difference, $p<0.05$. 
Table 3 Anthropometric characteristics of the alcohol-exposed and control children

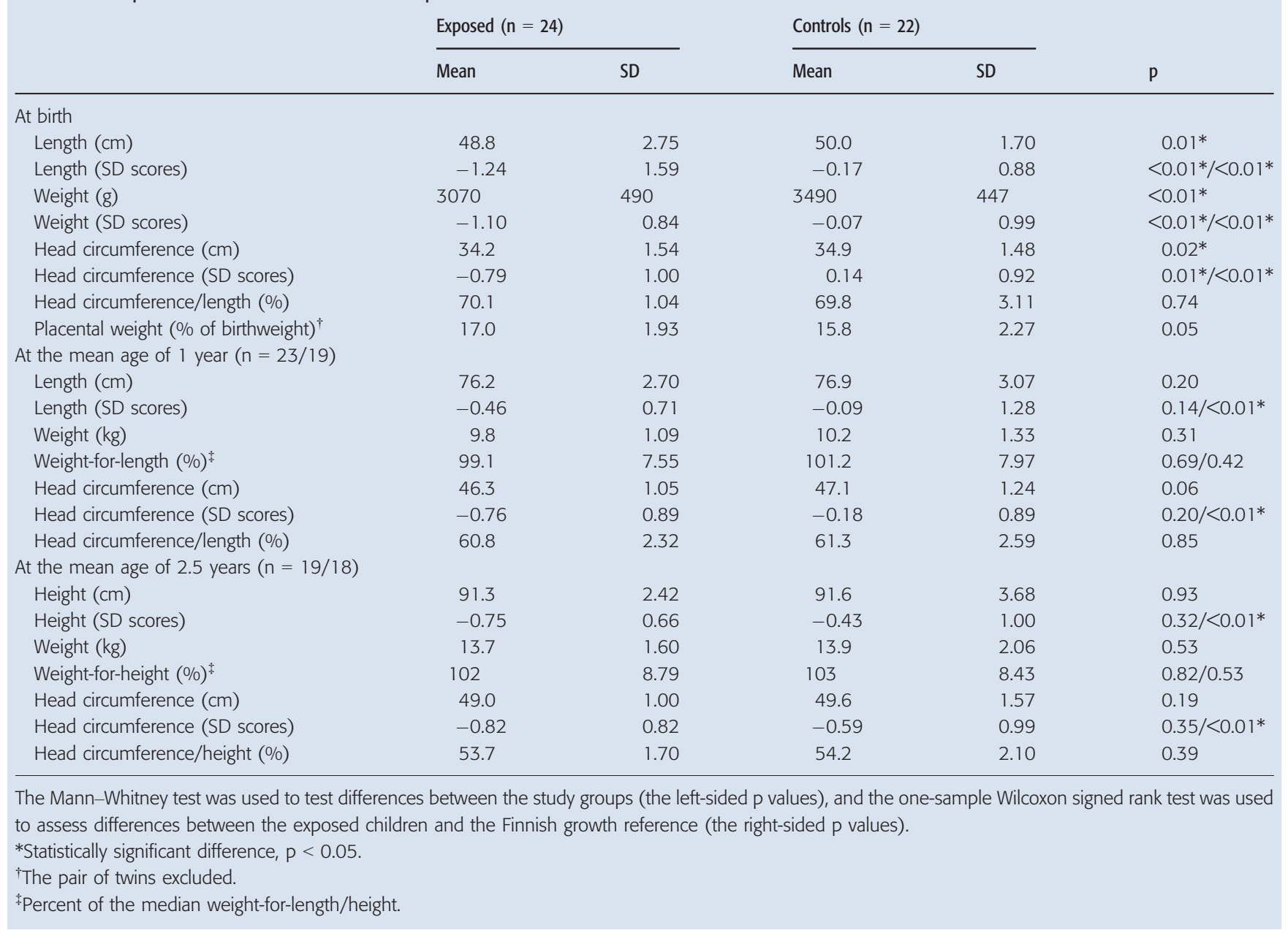

the exposed children scored lower than the controls in the general quotient and in the subscales of hearing and language and locomotor at the mean age of 2.5 years, their mean scores were close to the 50th percentile of the standard with a remarkable individual variation (Table 4).

\section{DISCUSSION}

In our study, alcohol exposure during pregnancy was already associated with decreased foetal head circumference at mid-pregnancy, but cerebellar changes were not detected. Follow-up of the exposed children showed that their head circumference and height were still found to be decreased at up to 2.5 years of age when compared with the Finnish growth reference. Although the exposed children scored lower than the controls in the general quotient and in the subscales of hearing and language and locomotor at the mean age of 2.5 years, their mean scores were close to the 50th percentile of the standard.

Our results were in line with previous studies showing that prenatal alcohol exposure was associated with decreased head circumference at birth $(21,22)$. Head circumference was shown to be a good predictor of brain volume in FASD (23). However, our study is apparently the first to show that decreased head circumference was already detectable at mid-pregnancy in alcohol-exposed foetuses. In addition to smaller head circumferences, the exposed foetuses had smaller biparietal and occipito-frontal diameters than the nonexposed ones at the mean gestational age of 20 weeks. To our knowledge, 3D ultrasonographically measured cerebellar volumes have not previously been reported in alcohol or drug-exposed foetuses. We did not find changes in foetal cerebellar volumes at the mean gestational age of 20 weeks, although cerebellar changes are common in alcohol-exposed children who have problems at school (7).

Given the pervasive nature of FASD, efforts have been made to identify a typical neurocognitive profile of prenatally alcohol-exposed children. Children with FAS suffer from widespread cognitive impairment, and prenatally alcohol-exposed individuals demonstrate impairments in multiple neurocognitive domains, with little evidence of a specific profile (14,24-26). It is evident that the development of neurocognitive problems becomes detectable over time, usually at school age, although the profile varies. Even though we were not able to show an association between 


\begin{tabular}{|c|c|c|c|c|c|}
\hline & \multicolumn{2}{|c|}{ Exposed children $(n=19)$} & \multicolumn{2}{|c|}{ Control children $(n=19)$} & \multirow[b]{2}{*}{$\mathrm{p}$} \\
\hline & Mean & SD & Mean & SD & \\
\hline \multicolumn{6}{|l|}{ At the mean age of 1 year } \\
\hline Locomotor (subquotient) & 101.1 & 10.0 & 93.8 & 15.1 & 0.20 \\
\hline Personal-social (subquotient) & 100.3 & 15.3 & 96.7 & 16.5 & 0.54 \\
\hline Hearing and language (subquotient) & 98.7 & 17.8 & 93.6 & 9.8 & 0.58 \\
\hline Eye and hand (subquotient) & 100.3 & 19.9 & 97.7 & 15.9 & 0.52 \\
\hline Performance (subquotient) & 105.5 & 13.9 & 106.1 & 21.4 & 0.70 \\
\hline General quotient & 101.5 & 10.9 & 97.8 & 13.1 & 0.42 \\
\hline \multicolumn{6}{|l|}{ At the mean age of 2.5 years $(n=19 / 16)$} \\
\hline Locomotor (percentile) & 51.6 & 31.8 & 76.9 & 25.9 & $0.04 *$ \\
\hline Personal-social (percentile) & 62.6 & 29.1 & 67.9 & 25.9 & 0.50 \\
\hline Hearing and language (percentile) & 41.2 & 30.8 & 66.2 & 34.3 & $0.02^{*}$ \\
\hline Eye and hand (percentile) & 48.0 & 28.8 & 56.3 & 26.5 & 0.45 \\
\hline Performance (percentile) & 41.5 & 29.3 & 54.1 & 29.2 & 0.16 \\
\hline Practical reasoning (percentile) & 54.0 & 24.5 & 66.6 & 27.0 & 0.12 \\
\hline General quotient (percentile) & 49.1 & 28.3 & 69.2 & 30.9 & $0.03 *$ \\
\hline
\end{tabular}

Mann-Whitney test was used to test differences between the groups.

*Statistically significant difference, $p<0.05$.

reduced foetal head circumference and developmental problems in infancy, we found that decreased head circumference was a risk factor for intellectual and behavioural problems. Stoler-Poria et al. (27) showed more behavioural problems in two- to six-year-old children who were diagnosed with microcephaly in utero than in control children.

The limitations of our study warrant explanations. Commitment to the follow-up study was an obvious limiting factor for the participation in the study, and therefore, the sample size remained regrettably small. Pregnant mothers encounter confusing feelings due to their pregnancy, and guilt about alcohol or drug abuse is evidently present. There were also alcohol abusers who were referred to the hospital at a later stage of pregnancy and could therefore not participate in the second-trimester ultrasonography. The reluctance of pregnant mothers to report prenatal drinking is a general challenge, and therefore, estimations of the degree of exposure may vary considerably (28). The mixed use of different substances has become a part of everyday life. In this study, we could not differentiate the potential synergism of alcohol and drugs or the effects of different drugs among the abusers. Adjustment for smoking was carried out for the foetal parameters, but not for the postnatal parameters. The majority of the foetuses were also exposed to smoking, which hampers head and body growth during pregnancy (29).

The methodological issues also caused limitations. GMDS has been shown to be a useful tool as a general indicator of subsequent development, but it only has a limited value as a predictor of hearing and speech in children below two years of age (30). Normal scores in the early years cannot preclude later neurological or cognitive problems. In addition, the investigators in this study could not be blinded for the alcohol or drug abuse of the mothers.

\section{CONCLUSION}

In summary, we found that a decrease in head circumference and occipito-frontal and biparietal distances could already be seen in alcohol or drug-exposed foetuses at the gestational age of 20 weeks. Cerebellar volume changes were not detected at this stage of pregnancy. The head circumferences and height of the exposed children remained reduced compared to the population reference at 2.5 years of age, while the weight-for-height and the head circumference to height ratio was normal. Early detection of foetal CNS changes in alcohol-exposed foetuses could be used to motivate maternal abstinence from alcohol and to reduce further detrimental alcohol-induced consequences.

\section{ACKNOWLEDGEMENTS}

We would like to thank the staff at the maternity clinic in Kuopio University Hospital, especially midwife Hanna Vehmas, and in Kuopio city public health centre for their assistance in the recruitment of the study subjects. Special thanks go to the mothers and children who participated in this study.

\section{FUNDING}

This study was supported by the National Graduate School of Clinical Investigation, Arvo and Lea Ylppö Foundation, the Finnish Foundation for Pediatric Research and Kuopio University Hospital.

\section{CONFLICT OF INTERESTS}

We declare that we have no conflict of interest. 


\section{References}

1. Pajulo M, Savonlahti E, Sourander A, Helenius H, Piha J. Antenatal depression, substance dependency and social support. J Affect Disord 2001; 65: 9-17.

2. Sarkola T, Kahila H, Gissler M, Halmesmaki E. Risk factors for out-of-home custody child care among families with alcohol and substance abuse problems. Acta Paediatr 2007; 96: 1571-6.

3. U.S. Department of health and human services. Substance abuse and mental health services administration: Results from the 2011 national survey on drug use and health: Summary of national findings. 2012; 2012: 174. Available from: URL: http://www. samhsa.gov/data/sites/default/files/NSDUHresults PDFWHTML2013/Web/NSDUHresults2013.pdf.

4. Hoyme HE, May PA, Kalberg WO, Kodituwakku P, Gossage JP, Trujillo PM, et al. A practical clinical approach to diagnosis of fetal alcohol spectrum disorders: clarification of the 1996 institute of medicine criteria. Pediatrics 2005; 115: 39-47.

5. National Center on Birth Defects and Developmental Disabilities Centers for Disease Control and Prevention Department of Health and Human Services in coordination with National Task Force on Fetal Alcohol Syndrome and Fetal Alcohol Effect American Academy of Pediatrics American College of Obstetricians and Gynecologists March of Dimes National Organization on Fetal Alcohol Syndrome. Fetal alcohol syndrome: Guidelines for referral and diagnosis. July 2004. Available at: http://www.cdc.gov/ncbddd/fasd/ documents/FAS_guidelines_accessible.pdf.

6. Sampson PD, Streissguth AP, Bookstein FL, Little RE, Clarren SK, Dehaene $\mathrm{P}$, et al. Incidence of fetal alcohol syndrome and prevalence of alcohol-related neurodevelopmental disorder. Teratology 1997; 56: 317-26.

7. Autti-Ramo I, Autti T, Korkman M, Kettunen S, Salonen O, Valanne L. MRI findings in children with school problems who had been exposed prenatally to alcohol. Dev Med Child Neurol 2002; 44: 98-106.

8. Donald KA, Eastman E, Howells FM, Adnams C, Riley EP, Woods RP, et al. Neuroimaging effects of prenatal alcohol exposure on the developing human brain: a magnetic resonance imaging review. Acta Neuropsychiatr 2015; 27: 25169.

9. Ekblad M, Korkeila J, Parkkola R, Lapinleimu H, Haataja L, Lehtonen L, et al. Maternal smoking during pregnancy and regional brain volumes in preterm infants. J Pediatr 2010; 156: 185, 90.e1.

10. Kfir M, Yevtushok L, Onishchenko S, Wertelecki W, Bakhireva $\mathrm{L}$, Chambers CD, et al. Can prenatal ultrasound detect the effects of in-utero alcohol exposure? A pilot study Ultrasound Obstet Gynecol 2009; 33: 683-9.

11. Handmaker NS, Rayburn WF, Meng C, Bell JB, Rayburn BB, Rappaport VJ. Impact of alcohol exposure after pregnancy recognition on ultrasonographic fetal growth measures. Alcohol Clin Exp Res 2006; 30: 892-8.

12. Wass TS, Persutte WH, Hobbins JC. The impact of prenatal alcohol exposure on frontal cortex development in utero. Am J Obstet Gynecol 2001; 185: 737-42.

13. Moe V. Foster-placed and adopted children exposed in utero to opiates and other substances: prediction and outcome at four and a half years. J Dev Behav Pediatr 2002; 23: 330-9.

14. Irner TB, Teasdale TW, Olofsson M. Cognitive and social development in preschool children born to women using substances. J Addict Dis 2012; 31: 29-44.
15. Hata T, Yanagihara T, Matsumoto M, Hanaoka U, Ueta M, Tanaka Y, et al. Three-dimensional sonographic features of fetal central nervous system anomaly. Acta Obstet Gynecol Scand 2000; 79: 635-9.

16. Saunders JB, Aasland OG, Babor TF, de la Fuente JR, Grant M. Development of the alcohol use disorders identification test (AUDIT): WHO collaborative project on early detection of persons with harmful alcohol consumption-II. Addiction 1993; 88: 791-804.

17. Huntley M. The Griffiths mental developmental scales from birth to 2 years. Oxford: The Test Agency Limited, 1996.

18. Luiz D, Barnard A, Knoesen N, Kotras N, Horrocks S, McAlinden P, et al. Griffiths mental development scalesextended revised two to eight years. Oxford: Hogrefe-The Test Agency Ltd, 2006.

19. Saari A, Sankilampi U, Hannila ML, Kiviniemi V, Kesseli K, Dunkel L. New Finnish growth references for children and adolescents aged 0 to 20 years: length/height-for-age, weightfor-length/height, and body mass index-for-age. Ann Med 2011; 43: 235-48.

20. Karvonen M, Hannila ML, Saari A, Dunkel L. New finnish reference for head circumference from birth to 7 years. Ann Med 2012; 44: 369-74.

21. Carter RC, Jacobson JL, Sokol RJ, Avison MJ, Jacobson SW. Fetal alcohol-related growth restriction from birth through young adulthood and moderating effects of maternal prepregnancy weight. Alcohol Clin Exp Res 2013; 37: 452-62.

22. Ortega-Garcia JA, Gutierrez-Churango JE, Sanchez-Sauco MF, Martinez-Aroca M, Delgado-Marin JL, Sanchez-Solis M, et al. Head circumference at birth and exposure to tobacco, alcohol and illegal drugs during early pregnancy. Childs Nerv Syst 2012; 28: 433-9.

23. Treit S, Zhou D, Andrew G, Chudley A, Beaulieu C. Is head circumference an accurate proxy for brain volume in individuals with fetal alcohol spectrum disorders? Int J Dev Neurosci 2015; 47: 84-5.

24. Ervalahti N, Korkman M, Fagerlund A, Autti-Ramo I, Loimu L, Hoyme HE. Relationship between dysmorphic features and general cognitive function in children with fetal alcohol spectrum disorders. Am J Med Genet A 2007; 143A: 2916-23.

25. Davies L, Dunn M, Chersich M, Urban M, Chetty C, Olivier L, et al. Developmental delay of infants and young children with and without fetal alcohol spectrum disorder in the Northern Cape Province, South Africa. Afr J Psychiatry (Johannesbg) 2011; 14: 298-305.

26. Quattlebaum JL, O'Connor MJ. Higher functioning children with prenatal alcohol exposure: is there a specific neurocognitive profile? Child Neuropsychol 2013; 19: 561-78.

27. Stoler-Poria S, Lev D, Schweiger A, Lerman-Sagie T, Malinger G. Developmental outcome of isolated fetal microcephaly. Ultrasound Obstet Gynecol 2010; 36: 154-8.

28. Manich A, Velasco M, Joya X, Garcia-Lara NR, Pichini S, Vall $\mathrm{O}$, et al. Validity of a maternal alcohol consumption questionnaire in detecting prenatal exposure. An Pediatr (Barc) 2012; 76: 324-8.

29. Salihu HM, Wilson RE. Epidemiology of prenatal smoking and perinatal outcomes. Early Hum Dev 2007; 83: 713-20.

30. Sutcliffe AG, Soo A, Barnes J. Predictive value of developmental testing in the second year for cognitive development at five years of age. Pediatr Rep 2010; 2: e15. 